Note

\section{An Arabinogalactan-rich Protein Containing 3-O-Methylrhamnose (Acofriose) in Young Plants of Osmunda japonica}

\author{
Takashi Akiyama, Ken Tanaka* \\ and Shigeru Yamamoto
}

\author{
Laboratories of Serology and Biochemistry and \\ *Chemistry, National Research Institute \\ of Police Science, 6 Sanban-cho, \\ Chiyoda-ku, Tokyo 102, Japan
}

Received March 23, 1987

Certain polysaccharide-proteins from plants inhibit hemagglutination by human blood specific antisera or lectins. ${ }^{1 \sim 6)}$ Here we report the occurrence in young ferns of 3-O-methylrhamnose (acofriose) containing an arabinogalactan-rich protein (AGRP) which strongly inhibits hemagglutination by human blood-group specific reagents.

AGRP was extracted from young plants of Osmunda japonica by the method described previously, ${ }^{4)}$ and was purified by ethanol precipitation $(50 \sim 80 \%, \mathrm{v} / \mathrm{v})$, then gelfiltration on a Toyopearl HW-55 (Toyosoda Manufacturing Co., Ltd.) column $(2.5 \mathrm{~cm} \times 60 \mathrm{~cm})$ equilibrated with distilled water. The purified AGRP was eluted as a single peak of carbohydrate which was monitored by the phenol- $\mathrm{H}_{2} \mathrm{SO}_{4}$ method $^{7)}$ from a Sepharose CL-6B (Pharmacia Fine Chemicals) column $(0.9 \mathrm{~cm} \times 100 \mathrm{~cm})$ equilibrated with $0.015 \mathrm{~m}$ sodium phosphate, $\mathrm{pH} 7.2$, containing $0.15 \mathrm{M} \mathrm{NaCl}$, and the maximum blood-group $\mathrm{H}$ activity that was measured by the published method ${ }^{1)}$ was also eluted at the same elution volume as the peak. AGRP was hydrolyzed in vacuo at $115^{\circ} \mathrm{C}$ for 22,48 , or $72 \mathrm{hr}$ with $4 \mathrm{~N}$ methanesulfonic acid containing $0.2 \% \quad 3-(2-$ aminoethyl)indole by the method of Simpson et al., ${ }^{8)}$ and its amino acids were analyzed on an Atto amino acid analyzer Type MLC-703. The major amino acids were glutamic acid, aspartic acid, serine, threonine, and hydroxyproline in the molar proportions of $19,12,11,11$, and $9 \%$, respectively. The amino acid residues accounted for $5 \sim 6 \%(\mathrm{w} / \mathrm{w})$ of AGRP. The carbohydrate content of AGRP was estimated to be $94 \sim 95 \%(\mathrm{w} / \mathrm{w})$ by the phenol$\mathrm{H}_{2} \mathrm{SO}_{4}$ method, ${ }^{7)}$ and a large amount of uronic acids (55 $\sim 57 \%$ of total carbohydrate) was also found in AGRP by a colorimetric assay. ${ }^{9)}$ The neutral sugars of AGRP were analyzed on a Shimadzu gas-liquid chromatograph (GLC) Type GC-R1A with a flame ionization detector. AGRP was hydrolyzed in a sealed glass tube with $2.5 \mathrm{M}$ trifluoroacetic acid for $8 \mathrm{hr}$ at $100^{\circ} \mathrm{C}$. Alditol derivatives of the corresponding neutral sugars in the hydrolyzate were separated in glass columns $(3 \mathrm{~mm} \times 2.1 \mathrm{~m})$ packed with $3 \%$ Silicone OV-225 on Gaschrom Q $\left(170 \sim 210^{\circ} \mathrm{C}, 2^{\circ} \mathrm{C} / \mathrm{min}\right)$ and $2 \%$ Silicone GEXF-1150 on Gaschrom P (95 $\left.170^{\circ} \mathrm{C}, 2^{\circ} \mathrm{C} / \mathrm{min}\right)$. The molar proportions of predominant neutral sugars in AGRP were an unknown sugar $(10 \%$ as rhamnose), rhamnose $(9 \%)$, arabinose $(12 \%)$, and galactose $(60 \%)$. We synthesized 3-O-methyl-Lrhamnose by regioselective methylation of an $n$-dibutyltin oxide $\left(\mathrm{Bu}_{2} \mathrm{SnO}\right)$ derivative of L-rhamnose as a possible candidate for the unknown sugar by a slight modification of the method of Haque et al. ${ }^{10)}$ A qualitative analysis of the alditol derivatives of the synthesized 3-Omethyl-L-rhamnose and the unknown sugar was done on a Hitachi-M80 combined gas chromatorgraph-mass spec-

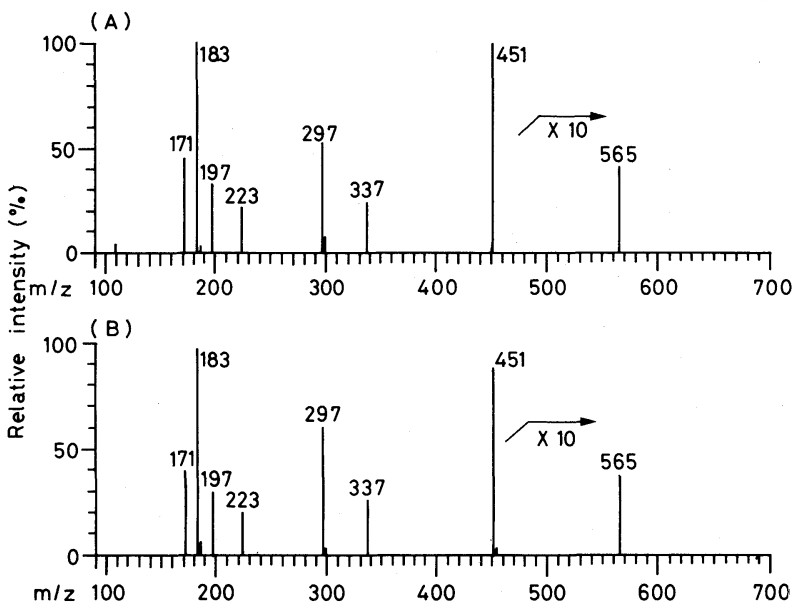

Fig. 1. Mass Spectra of Alditol Trifluoroacetates Derived from Sugars.

A, the unknown sugar in AGRP; B, the synthesized 3-O-methyl-L-rhamnose. 
Table I. Inhibition by Neutral Sugars Present IN THE Polysaccharide-ProteIn (AGRP) of Hemagglutination by Eel ANTI-H SERUM

\begin{tabular}{|c|c|c|}
\hline \multirow[t]{2}{*}{ Sugars } & \multicolumn{2}{|c|}{$\begin{array}{l}\text { Minimum amount of sugar } \\
\text { required for the complete } \\
\text { inhibition of eel anti-H } \\
\text { agglutinin }\end{array}$} \\
\hline & $(\mathrm{mg} / \mathrm{ml})^{c}$ & $(\mu \mathrm{mol} / \mathrm{ml})$ \\
\hline$L-F u \cos e^{a}$ & 0.08 & 0.47 \\
\hline 3-O-Methyl-L-rhamnose ${ }^{b}$ & 0.02 & 0.11 \\
\hline L-Rhamnose & $>5$ & $>30.5$ \\
\hline L-Arabinose & $>5$ & $>33.3$ \\
\hline D-Galactose & $>5$ & $>27.7$ \\
\hline
\end{tabular}

a L-Fucose was used as the positive control.

b 3-O-Methyl-L-rhamnose was synthesized and other sugars were obtained from commercial sources.

c Inhibitory activity is given as the concentration of sample $(\mathrm{mg} / \mathrm{ml})$ before addition of agglutinin and erythrocyte suspension.

trometer. The chemical ionization (CI) mass spectra of alditol trifluoroacetate derivatives of the two sugars were recorded under the following conditions: electron energy, $100 \mathrm{eV}$; ionizing current, $110 \mu \mathrm{A}$ (Fig. 1). The CI mass spectrum of the alditol trifluoroacetate of the unknown sugar appeared to be the same as that of the synthesized 3$O$-methyl-L-rhamnose, and the highest mass number peak at $m / z 565\left(\mathrm{MH}^{+}\right)$was assumed to be formed from the alditol trifluoroacetate derivative of 3-O-methyl-Lrhamnose which has molecular weight of 564. The electron impact (EI) mass spectra of the alditol acetate derivatives of the unknown sugar and the synthesized 3-O-methyl-Lrhamnose were also recorded (electron energy, $70 \mathrm{eV}$; ionizing current, $110 \mu \mathrm{A}$ ). The EI mass spectrum of the alditol acetate of the unknown sugar, a series of mass fragments, $m / z 43,87,101,129,143,189$, and 203 fully corresponded to those of 3-O-methyl-1,2,4,5-tetra- $O$ acetyl-6-deoxy-hexitol reported by Weckesser et al. ${ }^{11)}$ The chromatographic properties of the unknown sugar and the synthesized 3-O-methyl-L-rhamnose were also compared. Descending paper chromatography (PC) was done on Whatman No. 1 paper using 1-butanol-pyridinewater, $6: 4: 3$ (by volume). On PC the spots of the two sugars migrated with the same $R_{\mathrm{Rha}}$ value of $1.22 \sim 1.23$, and the spots were not stained with $\mathrm{AgNO}_{3}-\mathrm{NaOH}$, but they were with aniline hydrogen phthalate, GLC analysis showed that the unknown sugar has an identical retention time to the authentic 3-O-methyl-L-rhamnose. From these data the unknown sugar in AGRP was identified as $3-O$-methylrhamnose. It has been established that the terminal L-fucosyl residue is a prerequisite for both blood-group $\mathrm{H}$ and $\mathrm{Le}^{\mathrm{a}}$ activities of human and animal blood-group substances. ${ }^{12,3)}$ Since the bloodgroup activities were found by a hemagglutination inhition assay in AGRP regardless of its low fucose content (less than $1 \mathrm{~mol} \%$ ), it is suggested that other sugar residues might be responsible for the blood-group activities of AGRP. Among four major neutral sugars found in AGRP, only 3-O-methyl-L-rhamnose strongly inhibited eel anti-H agglutinin (Table I). This suggests that the 3-O-methylrhamnose is involved at least in the bloodgroup $\mathrm{H}$ activity of AGRP. 3-O-Methyl-L-rhamnose (acofriose) contaning AGRP which shows human bloodgroup activity has not hitherto been reported in a nonflowering plant, osmunda.

\section{REFERENCES}

1) G. F. Springer and P. K. Desai, Biochemistry, 10, 3749 (1971).

2) S. Yamamoto, J. Immunogenet., 2, 197 (1975).

3) S. Yamamoto, I. Sakai and S. Iseki, Immunol. Commun., 10, 215 (1981).

4) K. Nakamura, Y. Tsumuraya, Y. Hashimoto and S. Yamamoto, Agric. Biol. Chem., 48, 753.(1984).

5) Y. Tsumuraya, Y. Hashimoto, S. Yamamoto and N. Shibuya, Carbohyd. Res., 134, 215 (1984).

6) Y. Tsumuraya, K. Nakamura, Y. Hashimoto and S. Yamamoto, Agric. Biol. Chem., 48, 2915 (1984).

7) M. Dubois, K. A. Gilles, J. K. Hamilton, P. A. Rebers and F. Smith, Anal. Chem., 28, 350 (1965).

8) R. J. Simpson, M. R. Neuberger and T. -Y. Liu, J. Biol. Chem., 251, 1936 (1976).

9) T. Bitter and H. M. Muir, Anal. Biochem., 4, 330 (1962).

10) M. E. Haque, T. Kikuchi, K. Yoshimoto and Y. Tsuda, Chem. Pharm. Bull., 33, 2243 (1985).

11) J. Weckesser, H. Mayer and G. Drews, Eur. J. Biochem., 16, 158 (1970).

12) W. M. Watkins, "The Glycoprotein," B. B. A. Library, Vol. 5, Elsevier, Amsterdam, 1972, p. 830.

13) R. Oriol, J. Le Pendu and R. Mollicone, Vox Sang., 51, 161 (1986). 